Jurnal Akuntansi Bisnis, Vol. 19, No. 1, Maret 2021 ISSN 1412-775X (media cetak) | 2541-5204 (media online)

\title{
Determinan Fraudulent Financial Statement Melalui Perspektif Fraud Hexagon Theory Pada Perusahaan Pertambangan
}

\author{
Lailatul Imtikhani ${ }^{1 *}$, Sukirman ${ }^{2}$ \\ 1,2Jurusan Akuntansi, Fakultas Ekonomi, Universitas Negeri Semarang \\ *Corresponding author email: lailatulimtikhani1@gmail.com
}

\begin{abstract}
The purpose of this study is to examine the effect of fraud hexagon theory in detecting fraudulent financial statements. The element of fraud hexagon theory is measured by variables of financial stability, effective monitoring, auditor turnover, CEO duality, and political connections. The population of this study is mining sector companies listed on the Indonesia Stock Exchange (IDX) 2017-2019. The sampling technique used purposive sampling and obtained 41 companies with 123 observations. Data collection technique using documentation techniques with secondary data sourced from financial reports. The data analysis technique uses panel daya regression with Eviews 9 program. The test result show that financial stability and external pressure have a positive and significant effect on fraudulent financial statement. while the variables of effective monitoring, auditor change, director change, CEO duality, and political connection have no significant effect on fraudulent financial statement.
\end{abstract}

Keywords: fraud hexagon, fraudulent financial statement

\begin{abstract}
Abstrak
Penelitian ini bertujuan untuk menguji pengaruh fraud hexagon theory (tekanan, peluang, rasionalisasi, kapabilitas, ego, dan kolusi) dalam mendeteksi fraudulent financial statement. Elemen fraud hexagon theory diukur dengan variabel financial stability, external pressure, effective monitoring, auditor change, director change, CEO duality, dan political connection. Populasi penelitian ini adalah perusahaan sektor pertambangan yang terdaftar di Bursa Efek Indonesia (BEI) tahun 2017-2019. Teknik pengambilan sampel menggunakan purposive sampling dan diperoleh 41 perusahaan dengan 123 observasi. Teknik pengumpulan data menggunakan teknik dokumentasi dengan data sekunder yang bersumber dari laporan keuangan. Teknik analisis data menggunakan regresi data panel dengan program Eviews 9. Hasil pengujian menunjukkan bahwa financial stability dan external pressure berpengaruh positif dan signifikan terhadap fraudulent financial statement. sementara variabel effective monitoring, auditor change, director change, CEO duality, dan political connection tidak berpengaruh signifikan terhadap fraudulent financial statement.
\end{abstract}

Kata kunci: fraud hexagon theory, fraudulent financial statement 


\section{PENDAHULUAN}

Perusahaan menerbitkan laporan keuangan sebagai media komunikasi dan pertanggugjawaban manajemen kepada pihak internal maupun eksternal perusahaan (Yassha dan Zahara, 2020). Laporan keuangan merupakan salah satu hasil akhir dari proses akuntansi yang memberikan informasi mengenai posisi keuangan serta kinerja perusahaan yang berguna bagi para pemangku kepentingan dalam membuat keputusan ekonomi (Frymaruwah et al., 2020).

Pentingnya fungsi laporan keuangan menuntut manajemen perusahaan untuk menampilkan laporan keuangan yang terlihat baik, dan bebas dari salah saji material. Namun dalam realitas yang ada masih ditemukan salah saji material dan menyebabkan kecurangan dalam laporan keuangan yang menyesatkan para pengguna informasi akuntansi (Dumaria dan Majidah, 2019).

Association of Certified Fraud Examiners (ACFE) mendefinisikan fraud sebagai suatu tindakan secara sengaja dan melanggar hukum untuk tujuan tertentu. Dengan kata lain fraud merupakan suatu kecurangan dengan unsur tak terduga, tipu daya, licik, tidak jujur dan menghadirkan sesuatu yang tidak sesuai dengan keadaan yang merugikan pihak lain demi keuntungan pribadi (Sudarmanto, 2020)

Survei ACFE dalam Report to The Nation (RTTN) tahun 2020 menyatakan bahwa tindakan kecurangan laporan keuangan memiliki frekuensi terkecil namun memilki dampak kerugian yang besar dengan nilai rata-rata kerugian mencapai US\$954.000. Sektor pertambangan dan energi menduduki peringkat dua besar kerugian rata-rata tertinggi yang diakibatkan fraud.

Skandal Enron merupakan kasus fraud global pada sektor pertambangan yang melegenda. Kasus akuntansi tersebut diperkirakan menimbulkan kerugian sebesar US\$50 miliar, ditambah kerugian investor sebesar US\$32 miliar serta ribuan pegawai karyawan kehilangan dana pensiun mereka sekitar US\$1 miliar. Diketahui Enron adalah penyumbang ke-12 terbesar dana kampanye Presiden George Bush. Praktik kolusi tersebut memberikan privilage dan kemudahan bagi Enron untuk ikut andil merumuskan kebijakan minimal di bidang energi (majalah.tempo.co, 2002). Sementara di Indonesia tercatat beberapa kasus kecurangan laporan keuangan yang menyita perhatian publik, diantaranya yang dilakukan PT Garda Tujuh Buana Tbk (GTBO) tahun 2012 yang dituding melakukan manipulasi laporan keuangan karena adanya indikasi laporan keuangan tahun 2012 yang tidak sesuai. PT Timah Tbk (TINS) tahun 2015 diduga melaporkan keuangan fiktif untuk semester 1 tahun 2015.

Maraknya kasus kecurangan laporan keuangan mendorong para peneliti untuk terus mengembangkan teori tentang fraud. Vousinas (2019) mengembangkan model deteksi fraud terbaru yang dikenal dengan fraud hexagon theory. Penelitian ini menggunakan tujuh variabel untuk menggambarkan setiap komponen fraud hexagon. Tekanan diproksikan dengan financial stability dan external pressure, peluang diproksikan dengan effective monitoring, rasionalisasi diproksikan dengan auditor change, kapabilitas diproksikan dengan director change, ego diproksikan dengan CEO duality, dan kolusi diproksikan dengan political connection.

Penelitian yang dilakukan Sihombing et al. (2014), Lastanti (2020) dan Kusumosari dan Solikhah (2020) menunjukkan bahwa financial stability berpengaruh positif dan signifikan terhadap fraudulent financial statement. Sementara, Omukaga (2019), Ozcelik (2020), dan Sari 
dan Nugroho (2020) melaporkan bahwa financial stability tidak berpengaruh signifikan terhadap fraudulent financial statement. Penelitian yang menggunakan external pressure yang dilakukan Tessa dan Hartono (2016), Zaki (2017) menunjukkan adanya pengaruh positif dan signifikan terhadap fraudulent financial statement, sedangkan Faradiza (2019) dan Yusrianti et al. (2020) menunjukkan hasil external pressure berpengaruh tidak signifikan terhadap fraudulent financial statement. Hasil penelitian Septriyani dan Handayani (2018), dan Vidella dan Afiah (2020) menunjukkan bahwa effective monitoring berpengaruh positif dan signifikan terhadap fraudulent financial statement, sedangkan Tessa dan Hartono (2016) dan Pamungkas et al., (2018) melaporkan bukti bahwa effective monitoring tidak berpengaruh signifikan. Syahria (2019) dan Lastanti (2020) menunjukkan hasil bahwa auditor change berpengaruh positif signifikan terhadap fraudulent financial statement tetapi Sihombing et al. (2014) dan Septriyani dan Handayani (2018) menunjukkan hasil yang sebaliknya. Penelitian Pamungkas et al. (2018) dan Aviantara (2021) menunjukkan director change berpengaruh positif dan signifikan terhadap fraudulent financial statement, sedangkan Faradiza (2019) menunjukkan hasil yang sebaliknya. Penelitian Yang et al. (2017) menunjukkan CEO duality berpengaruh positif dan signifikan terhadap fraudulent financial statement, namun berlawanan dengan hasil penelitian dari Akbar (2017). Wang et al. (2017) dan Kusumosari dan Solikhah (2020) menunjukkan bahwa political connection berpengaruh positif dan signifikan namun Aprilia (2017) dan Sabrina et al. (2020) menunjukkan political connection tidak berpengaruh terhadap fraudulent financial statement.

Berdasarkan fenomena gap dan research gap maka penelitian ini menarik dan masih layak diujikan kembali. Penelitian ini merupakan pengembangan dari penelitian sebelumnya yang dilakukan oleh Kusumosari dan Solikhah (2020). Orisinalitas dalam penelitian ini adalah penggunaan sektor pertambangan sebagai sampel penelitian dan penggunaan politically exposed persons (PEPS) dalam menentukan perusahaan yang dikategorikan terkoneksi dengan politik dalam komponen collusion.

\section{TINJAUAN LITERATUR DAN PERUMUSAN HIPOTESIS}

\section{Teori Keagenan (Agency Theory)}

Jensen dan Meckling (1976) memperkenalkan hubungan keagenan sebagai suatu kontrak kerjasama antara principal dan agent yang mengakibatkan adanya pelimpahan wewenang dan pendelegasian pengambilan keputusan dari principal kepada agent. Adanya kontrak antara kedua belah pihak menimbulkan adanya masalah agensi. Principal selaku pemberi modal menginginkan return yang tinggi sedangkan pihak manajemen selaku agent menginginkan kompensasi yang besar. Pihak manajemen selaku pengelola perusahaan akan lebih banyak mengetahui informasi dalam perusahaan, sedangkan principal selaku pihak luar memiliki keterbatasan dalam mengetahui informasi kondisi perusahaan. Perbedaan kepentingan dan asimetris informasi antara agent dan principal akan memicu adanya tindakan fraudulent financial statement yang dilakukan oleh agent. 


\section{Fraud Hexagon Theory}

Menurut Vousinas (2019) fraud menjadi masalah internasional yang dapat terjadi di organisasi manapun dan kapanpun. ACFE (2017) menjelaskan fraudulent financial statement sebagai suatu kesalahan penyajian yang disengaja atas kondisi keuangan suatu perusahaan dengan salah saji yang disengaja atau penghilangan jumlah atau pengungkapan dalam laporan keuangan untuk menipu pengguna laporan keuangan. Fraud hexagon theory merupakan pengembangan dari teori fraud sebelumnya yang diperkenalkan dalam Vousinas (2019) dengan menambahkan satu komponen baru yaitu berupa kolusi. Hal ini didukung dengan hasil RTTN tahun 2020 yang menunjukkan bahwa 51\% dari kasus penipuan yang diteliti dilakukan oleh dua atau lebih pelaku yang berkolusi (ACFE, 2020).

\section{Financial stability dan fraudulent financial statement}

Financial stability menggambarkan kondisi keuangan suatu perusahaan. Kondisi keuangan perusahaan dapat dipengaruhi oleh kondisi ekonomi, industri, atau operasi entitas. Hal ini memicu sebuah tekanan bagi manajemen untuk menampilkan kondisi perusahaan dalam posisi stabil agar nilai perusahaan tetap terjaga (Skousen et al., 2009). Total aset perusahaan dapat mencerminkan kondisi stabilitas keuangan perusahaan.

Financial stability memiliki hubungan dengan teori agensi yang menyatakan adanya perbedaan kepentingan antara agent dan principal. Investor menginginkan return yang tinggi dari perusahaan. Besarnya total aset dapat dinilai memberikan imbal hasil yang maksimal bagi investor. Ketika perusahaan mampu mengelola aset dengan baik maka akan menghasilkan laba yang tinggi serta return yang tinggi bagi para investor. Hal ini menjadikan tekanan bagi manajemen sehingga memanfaatkan laporan keuangan sebagai media dalam menutupi kondisi keuangan yang tidak stabil dengan cara memanipulasi laporan keuangan agar dipandang mampu mengelola aset perusahaan secara baik dan memenuhi harapan dari investor (Ozcelik, 2020).

Penelitian ini didukung oleh penelitian Sihombing et al. (2014), Aprilia (2017), Faradiza (2019) yang menyatakan semakin tinggi rasio perubahan aset suatu perusahaan maka kemungkinan dilakukannya fraudulent financial statement semakin tinggi. Sehingga dapat ditarik hipotesis sebagai berikut:

\section{H1: Financial stability berpengaruh positif terhadap fraudulent financial statement.}

\section{External Pressure dan Fraudulent Financial Statement}

Tekanan eksternal merupakan tekanan yang dirasakan oleh manajemen perusahaan untuk mendapatkan sumber dana berupa hutang dan modal dari pihak eksternal (Skousen dan Wright, 2009). Sumber dana dapat diperoleh perusahaan apabila perusahaan menyajikan kinerja serta rasio keuangan yang baik, sehingga perusahaan diyakini mampu untuk mengembalikan pinjaman yang telah diperoleh serta mampu memberikan return yang tinggi.

Perbedaan kepentingan antara agent dan principal menyebabkan masalah agensi. Manajemen dituntut agar mendapatkan tambahan dana dari pihak ketiga untuk pengembangan lini bisnis. Hal ini menyebabkan tekanan bagi manajemen untuk menampilkan laporan keuangan agar 
terlihat baik dan memenuhi persyaratan dari pihak ketiga salah satunya dengan melakukan manipulasi laporan keuangan. Tekanan eksternal diukur dengan rasio leverage yaitu membandingkan total kewajiban dengan total aset. Rasio ini digunakan dalam menilai kemampuan perusahaan dalam mengembalikan pinjaman. Apabila perusahaan memiliki rasio yang tinggi, artinya perusahaan memiliki hutang yang besar sehingga risiko kredit yang dimiliki perusahaan juga tinggi. Hal ini didukung penelitian Sihombing et al. (2014), Tessa dan Hartono (2016) dan Zaki (2017) yang menyatakan semakin tinggi rasio leverage pada perusahaan maka kemungkinan adanya fraudulent financial statement juga semakin tinggi. Sehingga dapat ditarik hipotesis sebagai berikut:

\section{H2: External pressure berpengaruh positif terhadap fraudulent financial statement}

\section{Effective Monitoring dan Fraudulent Financial Statement}

Peluang seseorang untuk melakukan kecurangan dapat terjadi karena kurangnya kontrol dalam mencegah dan mendeteksi kecurangan. Sistem pengawasan yang efektif diperlukan untuk membatasi peluang seseorang untuk melakukan fraud. Adanya perbedaan kepentingan antara agent dan principal menyebabkan munculnya masalah agensi dan perlu adanya pengawasan kepada pihak agent. Posisi dewan Komisaris Independen beranggotakan pihak-pihak yang tidak memiliki hubungan kerabat, teman, atau saudara pada perusahaan diindikasikan mampu meningkatkan pengawasan internal perusahaan. Hal ini didukung oleh penelitian yang dilakukan Septriyani dan Handayani (2018), Omukaga (2019), dan Vidella dan Afiah (2020) yang menyatakan semakin tinggi persentase dewan Komisaris Independen dalam perusahaan maka menunjukkan semakin effektifnya pengawasan perusahaan dan berpengaruh negatif terhadap peluang terjadinya kecurangan laporan keuangan. Sehingga dapat ditarik hipotesis sebagai berikut: H3: Effective monitoring berpengaruh negatif terhadap fraudulent financial statement

\section{Auditor Change dan Fraudulent Financial Statement}

Rasionalisasi merupakan upaya mencari pembenaran atas tindakan kecurangan yang dilakukan. Salah satu proksi dalam rasionalisasi yaitu pergantian auditor. Perubahan auditor pada suatu perusahaan dapat dinilai sebagai suatu upaya untuk menghilangkan jejak fraud (fraud trial) yang ditemukan oleh auditor sebelumnya. Pergantian auditor atau KAP yang dilakukan oleh perusahaan dapat memicu konflik kepentingan antara agent dan principal semakin tinggi dan menyebabkan masalah adverse selection yang terjadi karena asimetris informasi antara kedua belah pihak yang dapat dimanfaatkan dalam melakukan kecurangan. Selain itu pergantian auditor mengakibatkan masa transisi dan stress period yang dapat dijadikan pembenaran bagi pihak agent dalam melakukan kecurangan. Hal tersebut sesuai dengan penelitian yang dilakukan Syahria (2019) dan Lastanti (2020) yang menyatakan bahwa semakin tinggi pergantian auditor dalam suatu perusahaan maka semakin tinggi indikasi seseorang dalam melakukan kecurangan. Sehingga dapat ditarik kesimpulan sebagai berikut:

H4: auditor change berpengaruh positif terhadap fraudulent financial statement 


\section{Director Change dan Fraudulent Financial Statement}

Capability merupakan sikap dan keterampilan individu yang memainkan peran besar dalam suatu tindakan kecurangan. Selain adanya peluang seseorang untuk bertindak kecurangan dan insentif atau tekanan serta rasionalisasi yang dapat memicu tindakan kecurangan, namun juga harus memiliki kemampuan untuk mengenali pintu mana yang terbuka sebagai peluang dan memanfaatkan dengan berjalan melewatinya, tidak hanya sekali, namun berkali-kali. Perbedaan kepentingan dan asimetris informasi antara agent dan principal akan menyebabkan masalah agensi. Pergantian direksi dapat menjadi suatu upaya dalam rangka memperbaiki kinerja direksi sebelumnya dengan melakukan perubahan susunan direksi ataupun perekrutan direksi baru yang dianggap lebih kompeten. Namun pergantian direksi juga dapat mengidentifikasikan suatu kepentingan tertentu untuk menggantikan jajaran sebelumnya yang tidak sejalan atau telah mengetahui adanya kecurangan pada perusahaan. Selain itu pergantian direksi juga akan menimbulkan stress period yang berdampak pada semakin terbukanya peluang bagi pelaku kecurangan yang memiliki kemampuan dalam melakukan kecurangan. Hal ini didukung oleh penelitian yang dilakukan Wolfe dan Hermanson (2004) dan Pamungkas et al. (2018) yang menyatakan bahwa semakin tinggi pergantian direksi maka semakin besar indikasi kecurangan laporan keuangan. Sehingga dapat ditarik hipotesis sebagai berikut:

\section{H5: Auditor change berpengaruh positif terhadap fraudulent financial statement}

\section{CEO Duality dan Fraudulent Financial Statement}

Ego ialah sikap superioritas yang timbul akibat keyakinan bahwa kontrol internal dan aturan tidak berlaku bagi diri mereka dan tidak akan terdeteksi dalam melakukan kecurangan. CEO duality ialah dominasi kekuasaan oleh CEO atau seseorang yang menduduki jabatan sebagai CEO sekaligus memiliki jabatan lain pada perusahaan. Jabatan ganda yang dimiliki seorang CEO akan menunjukkan sikap superioritas yang dapat mempengaruhi kebijakan perusahaan. Hal ini sejalan dengan teori agensi bahwa apabila CEO memegang lebih dari satu jabatan dapat menimbulkan sifat sombong karena merasa memiliki jabatan yang lebih dari satu sehingga dapat dengan leluasa memanfaatkan kekuasaan yang dimilikinya dengan melakukan kegiatan yang dapat menyebabkan kecurangan untuk kepentingan dirinya sendiri. Hal ini didukung penelitian yang dilakukan oleh Yang et al. (2017) dan Kusumosari dan Solikhah (2020) yang membuktikan semakin tinggi CEO duality akan menyebabkan semakin tingginya fraudulent financial statement. Sehingga dapat ditarik hipotesis sebagai berikut:

\section{H6: $C E O$ duality berpengaruh positif terhadap fraudulent financial statement}

\section{Political Connection dan Fraudulent Financial Statement}

Kolusi (collusion) mengacu pada kesepakatan antara beberapa orang, untuk melakukan suatu tindakan dengan tujuan jahat, seperti menipu pihak ketiga atas hak-haknya. Koneksi politik merujuk pada hubungan kedekatan antara jajaran perusahaan dengan politisi, pemerintah maupun para pejabat publik. Hubungan koneksi politik memberikan berbagai privilage dan kemudahan bagi perusahaan baik dalam perizinan sampai memperoleh pinjaman dana. Hubungan antar 
koneksi politik dan teori agensi ini muncul dengan adanya perbedaan tujuan dari agen dan principal. Hal ini dikarenakan agen menginginkan kesejahteraan mereka sendiri untuk mendapatkan keuntungan yang sebesar-besarnya atas kinerja mereka. Kemudahan dan hak istimewa yang dimiliki oleh perusahaan memungkinkan manajemen untuk melakukan kecurangan laporan keuangan. Hal ini didukung oleh penelitian yang dilakukan oleh Fitria (2013) Wang et al. (2017) dan Kusumosari dan Solikhah (2020) yang menyatakan semakin tinggi koneksi politik yang ada pada perusahaan maka akan semakin besar kemungkinan perusahaan melakukan fraudulent financial statement. Sehingga dapat ditarik hipotesis sebagai berikut:

H7: political connection berpengaruh positif terhadap fraudulent financial statement

\section{METODE PENELITIAN}

Penelitian ini merupakan penelitian kuantitatif. Data yang digunakan pada penelitian ini adalah data sekunder yang merupakan data yang bersumber dari laporan tahunan perusahaan tahun 2017-2019 yang bersumber dari situs www.idx.co.id. Populasi dalam penelitian ini adalah perusahaan sektor pertambangan tahun 2017-2019. Teknik pengambilan sampel yang menggunakan purposive sampling menghasilkan 123 observasi perusahaan seperti yang bisa dilihat pada Tabel 1.

Tabel 1. Kriteria Penentuan Sampel

\begin{tabular}{|c|c|c|}
\hline & Kriteria & Jumlah \\
\hline 1 & $\begin{array}{l}\text { Perusahaan sektor pertambangan yang terdaftar di Bursa Efek Indonesia } \\
\text { (BEI) dari tahun 2017-2019 }\end{array}$ & 48 \\
\hline 2 & $\begin{array}{l}\text { Perusahaan sektor pertambangan yang tidak terdaftar berturut-turut di BEI } \\
\text { dari periode } 2017-2019\end{array}$ & (4) \\
\hline 3 & $\begin{array}{l}\text { Data-data yang berkaitan dengan variabel penelitian tidak tersedia dengan } \\
\text { lengkap pada laporan tahunan yang dipublikasikan selama periode 2017- } \\
2019\end{array}$ & (3) \\
\hline \multirow[t]{2}{*}{4} & Perusahaan yang memenuhi kriteria tahun 2016-2019 & 41 \\
\hline & Observasi perusahaan yang tersedia selama tiga tahun $(41 \times 3)$ & 123 \\
\hline
\end{tabular}

Sumber: Data Sekunder yang Diolah (2021)

\section{Definisi dan Pengukuran Variabel}

Penelitian ini menggunakan satu variabel dependen dan tujuh variabel independen yang mana masing-masing memiliki proksi atau pengukurannya sendiri. Definisi operasional dan pengukuran variabel penelitian secara detail dapat dilihat pada Tabel 2. 
Jurnal Akuntansi Bisnis, Vol. 19, No. 1, Maret 2021 ISSN 1412-775X (media cetak) | 2541-5204 (media online)

\section{Tabel 2. Definisi Operasional}

\begin{tabular}{|c|c|c|c|}
\hline No & variabel & Definisi Operasional & Pengukuran \\
\hline 1 & $\begin{array}{l}\text { Fraudulent } \\
\text { Financial } \\
\text { Statements }\end{array}$ & $\begin{array}{l}\text { Tindakan manipulasi dan salah } \\
\text { saji material pada laporan } \\
\text { keuangan yang dilakukan } \\
\text { secara sengaja. }\end{array}$ & $\begin{array}{l}D A_{i t}=\frac{T A_{i t}}{A_{i t-1}}-N D A_{i t} \\
\text { (Dechow et al., 1995) }\end{array}$ \\
\hline 2 & $\begin{array}{l}\text { Financial } \\
\text { stability }\end{array}$ & $\begin{array}{l}\text { Kondisi yang } \\
\text { menggambarkan kestabilan } \\
\text { keuangan perusahaan }\end{array}$ & $\begin{array}{l}\text { ACHANGE }=\frac{\text { total Aset } t-\text { total aset } t-1}{\text { total aset } t-1} \\
\text { (Skousen et al., 2009) }\end{array}$ \\
\hline 3 & $\begin{array}{l}\text { External } \\
\text { pressure }\end{array}$ & $\begin{array}{l}\text { Tekanan yang bersumber dari } \\
\text { pihak ketiga }\end{array}$ & $\begin{array}{l}\text { LEV }=\frac{\text { Total Hutang }}{\text { Total Aset }} \\
\text { (Skousen et al., 2009) }\end{array}$ \\
\hline 4 & $\begin{array}{l}\text { Effective } \\
\text { monitoring }\end{array}$ & $\begin{array}{l}\text { keadaan dimana perusahaan } \\
\text { memiliki unit pengawasan } \\
\text { yang efektif dalam memantau } \\
\text { kinerja perusahaan }\end{array}$ & $\begin{array}{l}\text { BDOUT } \\
=\frac{\text { Jumlah dewan komisaris independen }}{\text { Total dewan komisaris }} \\
\text { (Skousen et al., 2009) }\end{array}$ \\
\hline 5 & $\begin{array}{l}\text { Auditor } \\
\text { Change }\end{array}$ & $\begin{array}{l}\text { Pergantian auditor yang } \\
\text { dilakukan oleh perusahaan }\end{array}$ & $\begin{array}{l}\text { Variabel dummy, apabila terdapat } \\
\text { pergantian kantor akuntan publik } \\
\text { selama periode } 2017-2019 \text { diberi kode } \\
\text { 1, dan sebaliknya diberi kode } 0 . \\
\text { (Tessa \& Hartono, 2016) }\end{array}$ \\
\hline 6 & $\begin{array}{l}\text { Director } \\
\text { Change }\end{array}$ & $\begin{array}{l}\text { Pergantian direktur yang } \\
\text { dilakukan oleh perusahaan. }\end{array}$ & $\begin{array}{l}\text { DCHANGE = Kode } 1 \text { apabila terdapat } \\
\text { pergantian direksi dan kode } 0 \text { jika tidak } \\
\text { terdapat pergantian direksi. } \\
\text { (Tessa \& Hartono, 2016) }\end{array}$ \\
\hline 7 & $\begin{array}{l}\text { CEO } \\
\text { Duality }\end{array}$ & $\begin{array}{l}\text { Jabatan ganda yang dimiliki } \\
\text { CEO dalam perusahaan }\end{array}$ & $\begin{array}{l}\text { CEODUAL = kode } 1 \text { apabila terdapat } \\
C E O \text { Duality dalam perusahaan dan } \\
\text { kode } 0 \text { jika sebaliknya. } \\
\text { (Putri dan Deviesa, 2017) }\end{array}$ \\
\hline 8 & $\begin{array}{l}\text { Political } \\
\text { connection }\end{array}$ & 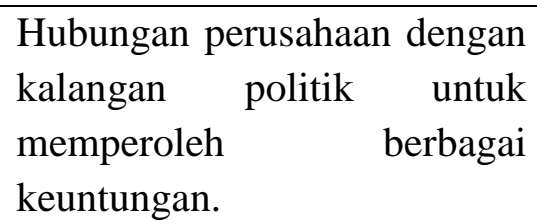 & $\begin{array}{l}\text { Variabel dummy, yaitu nilai } 1 \text { untuk } \\
\text { perusahaan yang merupakan atau } \\
\text { terkoneksi dengan PEPs, dan nilai } 0 \\
\text { untuk sebaliknya. }\end{array}$ \\
\hline
\end{tabular}


Jurnal Akuntansi Bisnis, Vol. 19, No. 1, Maret 2021 ISSN 1412-775X (media cetak) | 2541-5204 (media online)

Teknik pengumpulan data dilakukan dengan menggunakan metode dokumentasi. Data diperoleh dari data laporan tahunan perusahaan yang terdapat pada website milik perusahaan dan data yang dipublikasikan oleh Bursa Efek Indonesia (BEI).

\section{Model Regresi}

Alat analisis yang digunakan dalam penelitian ini adalah analisis statistik deskriptif dan analisis statistik inferensial dengan menggunakan model regresi berganda. Model regresi yang digunakan untuk pengujian hipotesis adalah sebagai berikut:

$$
\mathrm{DA}=\mathrm{FS}+\mathrm{EP}+\mathrm{EM}+\mathrm{AC}+\mathrm{DC}+\mathrm{CD}+\mathrm{PC}+\varepsilon
$$

Keterangan: $\mathrm{DA}=$ Fraudulent financial statement, $\mathrm{FS}=$ Financial Stability, $\mathrm{EP}=$ External Pressure, $\mathrm{EM}=$ Effective Monitoring, $\mathrm{AC}=$ Auditor Change, $\mathrm{DC}=$ Director Change, $\mathrm{CD}=C E O$ Duality, dan $\mathrm{PC}=$ Political Connection.

\section{HASIL DAN PEMBAHASAN}

\section{Statistik Deskriptif}

Analisis statistik deskriptif bertujuan untuk mendeskripsikan nilai rata-rata (mean), maksimum, minimum dan standar deviasi dari variabel penelitian. Hasil statistik deskriptif tersaji dalam Tabel.3.

Tabel 3. Statistik Deskriptif

\begin{tabular}{|l|l|l|l|l|l|}
\hline Variabel & $\mathrm{N}$ & Minimum & Maksimum & Rata-rata & Std. Deviasi \\
\hline DA & 123 & -0.061281 & 0.108584 & 0.001797 & 0.012964 \\
\hline FS & 123 & -2.868031 & 0.600458 & 0.021785 & 0.357763 \\
\hline EP & 123 & 0.026540 & 1.308902 & 0.515602 & 0.256624 \\
\hline EM & 123 & 0.200000 & 0.666667 & 0.406262 & 0.096324 \\
\hline AC & 123 & 0.000000 & 1.000000 & 0.146341 & 0.354894 \\
\hline DC & 123 & 0.000000 & 1.000000 & 0.439024 & 0.498298 \\
\hline CD & 123 & 0.000000 & 1.000000 & 0.138211 & 0.346533 \\
\hline PC & 123 & 0.000000 & 1.000000 & 0.617886 & 0.487892 \\
\hline
\end{tabular}

Sumber: Hasil Pengolahan Data (2021)

Berdasarkan tabel diatas dapat diketahui dalam penelitian ini menggunakan 123 observasi perusahaan. Indikasi adanya fraudulent financial statement tercermin dari discretionary accrual (DA) yang diestimasi menggunakan model Jones yang dimodifikasi. Variabel tersebut memiliki 
Jurnal Akuntansi Bisnis, Vol. 19, No. 1, Maret 2021 ISSN 1412-775X (media cetak) | 2541-5204 (media online)

nilai minimum sebesar -0,061281 yang dimiliki oleh PT. Cakra Mineral Tbk (CKRA) tahun 2018 dengan indikasi penurunan laba (income decreasing). Nilai maksimum pada PT Capitalinc Investama Tbk (MTFN) 2017 sebesar 0,108584 yang mengindikasikan peningkatan laba (income increasing). Nilai rata-rata DA senilai 0,001797 mengindikasikan bahwa perusahaan yang dijadikan objek penelitian melakukan fraudulent financial statement dengan cara menaikkan laba melalui manajemen laba. Nilai standar deviasi senilai 0,012964 yang lebih besar dari nilai ratarata sehingga data menyebar secara heterogen.

Variabel financial stability memiliki nilai minimum -2,868031 (CKRA 2018) dan maksimum 0,600458 (MTFN 2017). Sedangkan nilai rata-rata sebesar 0,021785 dan standar deviasi sebesar 0,357763 , sehingga data menyebar secara heterogen.

Variabel external pressure memiliki nilai minimum 0,026540 (APEX 2019) dan nilai maksimum 0,02654 (CKRA 2017). Sedangkan nilai rata-rata sebesar 0,515602 dan standar deviasi sebesar 0,256624 . Nilai standar deviasi yang lebih kecil dari nilai rata-rata menunjukkan bahwa variasi data cukup rendah.

Variabel effective monitoring memiliki nilai minimum 20\% (INCO 2019) dan nilai maksimum sebesar 67\% (DOID 2017, MITI 2019, TOBA 2019). Sementara nilai rata-rata menunjukkan nilai 0,406262 dan standar deviasi senilai 0,096324 yang menunjukkan lebih kecil dari rata-rata sehingga variasi data cukup rendah.

Variabel auditor change yang diukur dengan variabel dummy menunjukkan bahwa dari 123 observasi yang digunakan, terdapat $15 \%$ atau 18 perusahaan melakukan pergantian auditor (skor 1). Sementara itu, 85\% atau 105 tidak melakukan pergantian auditor (skor 0). Sehingga mayoritas perusahaan sampel tidak melakukan pergantian auditor. Nilai rata-rata dari variabel auditor change sebesar 0,146341. Sedangkan nilai standar deviasi untuk variabel auditor change adalah 0,354894 . Nilai tersebut lebih besar dari nilai rata-rata, sehingga menunjukkan persebaran data yang bervariasi.

Variabel director change yang diukur dengan variabel dummy menunjukkan bahwa 44\% atau 54 perusahaan melakukan pergantian direksi (skor 1). Sementara itu, 66\% atau 69 perusahaan tidak melakukan pergantian auditor (skor 0). Sehingga mayoritas dari perusahaan sampel tidak melakukan pergantian direktur. Nilai rata-rata untuk variabel director change sebesar 0,439024. Sedangkan nilai standar deviasi sebesar 0,498298. Sehingga memiliki persebaran data yang bervariasi.

Variabel CEO duality diukur dengan variabel dummy menunjukkan dari 14\% atau 17 perusahaan memiliki CEO duality (skor 1). Sedangkan sebanyak 86\% atau 106 perusahaan tidak memiliki CEO duality (skor 0). Sehingga mayoritas perusahaan sampel tidak memiliki CEO duality. Nilai rata-rata variabel $C E O$ duality sebesar 0,138211. Sedangkan nilai standar deviasi variabel $C E O$ duality sebesar 0,346533. Nilai tersebut lebih besar dari nilai rata-rata, sehingga variabel $C E O$ duality memiliki persebaran yang bervariasi.

Variabel political connection yang diukur dengan variabel dummy menunjukkan $62 \%$ atau 76 perusahaan memiliki hubungan politik (skor 1). Sedangkan sebanyak $38 \%$ atau 47 perusahaan tidak memiliki hubungan politik (skor 0). Sehingga mayoritas perusahaan pertambangan memiliki 
Jurnal Akuntansi Bisnis, Vol. 19, No. 1, Maret 2021

ISSN 1412-775X (media cetak) | 2541-5204 (media online)

jajaran manajemen yang terkoneksi dengan PEPs. Nilai rata-rata variabel political connection sebesar 0,617886. Sedangkan nilai standar deviasi variabel political connection sebesar 0,487892. Nilai ini lebih besar dari nilai rata-rata, sehingga variabel political connection memiliki persebaran yang bervariasi.

\section{Uji Asumsi Klasik}

Uji asumsi klasik yang digunakan pada penelitian ini adalah uji multikolinearitas dan uji heterokedastisitas. Hasil uji multikolinearitas menunjukkan bahwa tingkat korelasi satu variabel dengan variabel independen lainnya dibawah 0,8 yang artinya data pada penelitian ini terbebas dari masalah multikolinearitas, sehingga dapat dilakukan tahapan uji asumsi klasik berikutnya. Hasil uji heterokedastisitas menunjukkan bahwa data yang digunakan dalam penelitian ini terbebas dari adanya heterokedastisitas karena seluruh variabel independen memiliki nilai prob. lebih besar dari 0,05 .

\section{Hasil dan Pembahasan}

Penelitian ini menggunakan regresi berganda untuk pengujian hipotesis dan hasilnya dapat dilihat pada Tabel 4. Dari tujuh hipotesis yang dikemukakan ada dua yang diterima secara signifikan yaitu $\mathrm{H} 1$ dan $\mathrm{H} 2$. Hasil ini menunjukkan bahwa semakin tinggi financial stability dan external pressure, maka semakin tinggi pula fraudulent financial statement.

Tabel 4. Hasil Regresi

\begin{tabular}{ccccc}
\hline \hline Variable & Coefficient & Std. Error & t-Statistic & Prob. \\
\hline \hline FS & 0.028716 & 0.004277 & 6.714457 & 0.0000 \\
EP & 0.029627 & 0.014547 & 2.036678 & 0.0452 \\
EM & 0.025843 & 0.022661 & 1.140421 & 0.2577 \\
AC & -0.002413 & 0.003738 & -0.645514 & 0.5206 \\
DC & 0.002894 & 0.002972 & 0.973588 & 0.3334 \\
CD & 0.003754 & 0.013267 & 0.282985 & 0.7780 \\
PC & 0.002259 & 0.007731 & 0.292184 & 0.7710 \\
\hline
\end{tabular}

Sumber: Hasil Pengolahan Data Eviews 9 (2021)

\section{Pengaruh Financial Stability Terhadap Fraudulent Financial Statement}

Berdasarkan hasil uji hipotesis dalam penelitian ini menunjukkan bahwa hipotesis pertama (H1) diterima. Hal ini menunjukkan bahwa financial stability yang diukur dengan perubahan total aset (ACHANGE) berpengaruh positif dan signifikan terhadap fraudulent financial statement. 
Pengaruh positif financial stability terhadap fraudulent financial statement dalam penelitian ini sesuai dengan agency theory yang dijadikan acuan.

Teori agensi menjelaskan adanya perbedaan kepentingan antara pihak principal dan agent. Investor sebagai pihak principal menginginkan return yang tinggi atas investasinya, sedangkan manajemen sebagai pihak agent menginginkan kompensasi yang tinggi atas kinerjanya. Hal ini menimbulkan tekanan bagi manajemen untuk selalu menampilkan kinerja perusahaan yang stabil, agar para investor tidak mengurangi aliran dana investasi di tahun berikutnya. Banyaknya total aset yang dimiliki perusahaan menjadi daya tarik bagi para investor. Kecenderungan manajemen untuk menunjukkan total aset yang tinggi tersebut membuat pihak manajemen berpotensi untuk melakukan fraudulent financial statement. Dengan demikian, hasil dari penelitian ini mampu menjawab teori agensi yang menunjukkan bahwa financial stability berpengaruh terhadap fraudulent financial statement.

Hasil penelitian ini sejalan dengan penelitian yang dilakukan Sihombing et al. (2014), Aprilia (2017), Faradiza (2019), Yusrianti et al. (2020), Syahria (2019), Lastanti (2020) dan Kusumosari dan Solikhah (2020) yang menunjukkan bahwa financial stability berpengaruh positif dan signifikan terhadap fraudulent financial statement. Namun bertolak belakang dengan hasil temuan dari Zaki (2017), Omukaga (2019), Ozcelik (2020), Frymaruwah et al. (2020), dan Sari dan Nugroho (2020) yang menunjukkan bahwa financial stability tidak berpengaruh terhadap fraudulent financial statement.

\section{Pengaruh External Pressure Terhadap Fraudulent Financial Statement}

Berdasarkan hasil uji hipotesis dalam penelitian ini menunjukkan bahwa hipotesis kedua (H2) diterima. Hal ini menunjukkan bahwa external pressure yang diukur dengan rasio leverage (LEV) berpengaruh positif dan signifikan terhadap fraudulent financial statement. Pengaruh positif external pressure terhadap fraudulent financial statement dalam penelitian ini sesuai dengan agency theory yang dijadikan acuan.

Teori agensi menyatakan adanya perbedaan kepentingan antara principal dan agen. Perbedaan kepentingan ini menyebabkan manajemen sebagai agen mengalami tekanan untuk memenuhi harapan principal, salah satunya yaitu untuk mendapatkan sumber dana dan pembiayaan dari pihak eksternal. Tekanan tersebut mendorong manajemen untuk melakukan segala cara agar memenuhi harapan pihak eksternal dengan menampilkan kinerja yang terbaik, meskipun dilakukan dengan melakukan manipulasi laporan keuangan. Dengan demikian, temuan dalam penelitian ini mampu menjawab teori tersebut, karena berdasarkan uji hipotesis menunjukkan bahwa external pressure berpengaruh positif dan signifikan terhadap fraudulent financial statement.

Hasill penelitian ini sejalan dengan penelitian Sihombing et al. (2014), Tessa dan Hartono (2016), dan Zaki (2017) yang menunjukkan bahwa semakin tinggi rasio leverage maka semakin tinggi pula kemungkinan perusahaan melakukan fraudulent financial statement. Namun, penelitian ini bertolak belakang dengan Aprilia (2017), Faradiza (2019), Yusrianti et al. (2020), Frymaruwah et al. (2020), Sari dan Nugroho (2020) dan Kusumosari dan Solikhah (2020) yang menyatakan bahwa external pressure tidak berpengaruh terhadap fraudulent financial statement. 
Jurnal Akuntansi Bisnis, Vol. 19, No. 1, Maret 2021

ISSN 1412-775X (media cetak) | 2541-5204 (media online)

\section{Pengaruh Effective Monitoring Terhadap Fraudulent Financial Statement}

Berdasarkan hasil uji hipotesis dalam penelitian ini menunjukkan bahwa hipotesis ketiga (H3) ditolak. Hal ini menunjukkan bahwa effective monitoring yang diukur dengan persentase komisaris independen tidak berpengaruh terhadap fraudulent financial statement. Dengan demikian penelitian ini tidak mendukung teori agensi yang menjadi acuan.

Teori agensi menjelaskan adanya pemberian wewenang dari pihak principal kepada pihak agen dalam melakukan kepentingan principal, namun manajemen selaku agen dalam mengelola perusahaan cenderung mementingkan kepentingan pribadi. Komisaris independen sebagai wakil dari para pemegang saham seharusnya dapat menjalankan tugasnya dalam melakukan pengawasan. Namun tak jarang pengangkatan komisaris independen ini hanya sebatas pemenuhan persyaratan regulasi, sehingga tidak berdampak pada sistem pengawasan yang ada. Hal ini dimungkinkan menjadi penyebab kenapa effective monitoring tidak berpengaruh terhadap fraudulent financial statement.

Penelitian ini sejalan dengan penelitian Tessa dan Hartono (2016), Pamungkas et al. (2018), dan Sari dan Nugroho (2020) yang menyatakan bahwa effective monitoring tidak berpengaruh terhadap fraudulent financial statement. Namun bertolak belakang dengan penelitian Septriyani dan Handayani (2018), Vidella dan Afiah (2020), Ozcelik (2020), dan Omukaga (2019) yang menyatakan bahwa effective monitoring berpengaruh terhadap fraudulent financial statement.

\section{Pengaruh Auditor Change Terhadap Fraudulent Financial Statement}

Berdasarkan hasil uji hipotesis dalam penelitian ini menunjukkan bahwa hipotesis keempat (H4) ditolak. Hal ini menunjukkan bahwa auditor change yang diukur dengan variabel dummy tidak berpengaruh terhadap fraudulent financial statement. Dengan demikian penelitian ini tidak mendukung teori agensi yang menjadi acuan.

Teori agensi menyatakan adanya perbedaan kepentingan antara agen dan principal. Perbedaan kepentingan ketika manajemen sebagai agen akan melakukan pergantian auditor dengan tujuan kepentingan pribadi. Namun, temuan dalam penelitian ini tidak mampu menjawab teori tersebut karena berdasarkan hasil uji hipotesis menunjukkan bahwa variabel auditor change tidak berpengaruh terhadap fraudulent financial statement. Hal tersebut dapat disebabkan karena perusahaan merasa tidak puas atas kinerja Kantor Akuntan Publik (KAP) pada periode sebelumnya. Pergantian auditor dilakukan untuk memperbaiki kinerja auditor eksternal pada periode sebelumnya dengan tujuan meningkatkan kualitas laporan keuangan perusahaan sehingga investor akan tertarik untuk berinvestasi pada perusahaan. Hal ini sesuai dengan Peraturan Otoritas Jasa Keuangan Nomor 13/POJK.03/2017 dimana pihak yang melaksanakan kegiatan Jasa Keuangan wajib membatasi penggunaan jasa audit atas informasi keuangan historis tahunan dari AP yang sama paling lama 3 (tiga) tahun buku berturut-turut.

Penelitian ini sejalan dengan penelitian Sihombing et al. (2014), Septriyani dan Handayani (2018), Tiapandewi et al. (2020), Alfina dan Amrizal (2020), dan Sari dan Nugroho (2020) yang menunjukkan bahwa pergantian auditor tidak berpengaruh terhadap kecurangan laporan keuangan. 
Jurnal Akuntansi Bisnis, Vol. 19, No. 1, Maret 2021

ISSN 1412-775X (media cetak) | 2541-5204 (media online)

Namun bertolak belakang dengan penelitian Syahria (2019) dan Lastanti (2020) yang menyatakan bahwa pergantian auditor berpengaruh positif terhadap kecurangan laporan keuangan.

\section{Pengaruh Director Change Terhadap Fraudulent Financial Statement}

Berdasarkan hasil uji hipotesis dalam penelitian ini menunjukkan bahwa hipotesis kelima (H5) ditolak. Hal ini menunjukkan bahwa director change yang diukur dengan variabel dummy tidak berpengaruh terhadap fraudulent financial statement. Dengan demikian penelitian ini tidak mendukung teori agensi yang menjadi acuan.

Penelitian ini tidak mendukung teori agensi, yang menyatakan bahwa terdapat perbedaan kepentingan antara agen dan principal. Perbedaan kepentingan membuat manajemen sebagai agen akan melakukan pergantian direksi dengan tujuan kepentingan pribadi. Hasil penelitian menunjukkan bahwa director change tidak berpengaruh terhadap fraudulent financial statement. Hal tersebut dapat disebabkan karena director change yang dilakukan oleh perusahaan bertujuan untuk mengganti direksi yang lebih berkompeten dan dapat bekerja lebih maksimal dibandingkan direksi pada periode sebelumnya sehingga mampu memperbaiki serta meningkatkan kinerja perusahaan. Kinerja perusahaan yang baik tersebut akan menarik investor untuk berinvestasi pada perusahaan.

Penelitian ini sejalan dengan penelitian oleh Sihombing et al. (2014), Faradiza (2019), Syahria (2019), Sari dan Nugroho (2020) dan Lastanti (2020) yang menyatakan bahwa directors change tidak berpengaruh terhadap fraudulent financial statement. Namun penelitian ini bertolak belakang dengan penelitian Pamungkas et al. (2018) dan Aviantara (2021) yang menyatakan bahwa directors change berpengaruh terhadap fraudulent financial statement.

\section{Pengaruh CEO Duality Terhadap Fraudulent Financial Statement}

Berdasarkan hasil uji hipotesis dalam penelitian ini menunjukkan bahwa hipotesis keenam (H6) ditolak. Hal ini menunjukkan bahwa CEO duality yang diukur dengan variabel dummy tidak berpengaruh terhadap fraudulent financial statement. Dengan demikian penelitian ini tidak mendukung teori agensi yang menjadi acuan.

Penelitian ini tidak mendukung teori agensi yang menyatakan bahwa terdapat perbedaan kepentingan antara agen dan principal. Perbedaan kepentingan berupa keinginan dari manajemen sebagai agen untuk memperoleh kompensasi yang tinggi atas kinerja perusahaan yang telah dikelolanya. CEO duality yang tidak berpengaruh terhadap fraudulent financial statement dapat disebabkan karena CEO yang memiliki lebih dari satu jabatan lebih memanfaatkan jabatan yang dimilikinya untuk meningkatkan kinerja perusahaan serta untuk menjaga kinerja dirinya sendiri untuk mempertahankan posisinya dalam perusahaan. Faktor lain yang menyebabkan tidak berpengaruhnya $C E O$ duality terhadap fraudulent financial statement yaitu dikarenakan peran Dewan Komisaris telah maksimal dalam mengawasi kinerja CEO, sehingga CEO tidak dapat menyalahgunakan kekuasaan yang dimilikinya untuk melakukan fraud (Indriyani dan Suryandari, 2021).

Dengan demikian, penelitian ini sejalan dengan penelitian yang dilakukan oleh Akbar (2017) dan Indriyani dan Suryandari (2021) yang menyatakan bahwa CEO duality tidak 
berpengaruh terhadap fraudulent financial statement. Namun bertolak belakang dengan penelitian yang dilakukan oleh Kusumosari dan Solikhah (2020) dan Yang et al. (2017) yang menyatakan bahwa ego yang diproksikan dengan $C E O$ duality berpengaruh terhadap fraudulent financial statement.

\section{Pengaruh Political Connection Terhadap Fraudulent Financial Statement}

Berdasarkan hasil uji hipotesis dalam penelitian ini menunjukkan bahwa hipotesis ketujuh (H7) ditolak. Hal ini menunjukkan bahwa political connection yang diukur dengan variabel dummy tidak berpengaruh terhadap fraudulent financial statement. Dengan demikian penelitian ini tidak dapat mendukung teori agensi yang menjadi acuan.

Penelitian ini tidak dapat mendukung teori agensi yang menjelaskan bahwa perbedaan kepentingan antara manajemen sebagai agen dengan pemegang saham sebagai principal. Penelitian ini menunjukkan bahwa tidak adanya pengaruh yang signifikan bahwa kolusi yang diproksikan dengan koneksi politik terhadap kecurangan laporan keuangan. Hal ini disebabkan karena pihak manajemen yang terkoneksi dengan politik tidak serta merta memanfaatkan jabatannya demi keuntungan pribadi dan kelompoknya, sehingga koneksi politik tidak berpengaruh terhadap kecurangan laporan keuangan.

Dengan demikian penelitian ini bertolak belakang dengan penelitian yang dilakukan oleh Kusumosari dan Solikhah (2020) yang menyatakan bahwa koneksi politik berpengaruh terhadap fraudulent financial statement.

\section{SIMPULAN DAN SARAN}

\section{Simpulan}

Berbagai kasus kecurangan laporan keuangan yang terjadi selama ini telah mendorong akademisi untuk memahami faktor-faktor yang mendorong orang melakukan kecurangan. Namun hasil-hasil penelitian terdahulu menunjukkan hasil yang saling bertentangan. Penelitian ini bertujuan untuk menguji kembali faktor-faktor yang mempengaruhi kecurangan laporan keuangan dengan menggunakan tujuh variabel untuk menggambarkan setiap komponen fraud hexagon. Tekanan diproksikan dengan financial stability dan external pressure, peluang diproksikan dengan effective monitoring, rasionalisasi diproksikan dengan auditor change, kapabilitas diproksikan dengan director change, ego diproksikan dengan CEO duality, dan kolusi diproksikan dengan political connection.

Hasil pengujian hipotesis menunjukkan bahwa financial stability dan external pressure berpengaruh positif signifikan terhadap fraudulent financial statement. Sementara itu, effective monitoring, auditor change, director change, CEO duality dan political connection tidak berpengaruh signifikan terhadap fraudulent financial statement.

\section{Saran}

Penelitian selanjutnya diharapkan menambahkan variabel independen lainnya dikarenakan nilai adjusted $R^{2}$ dalam penelitian ini yang masih relatif kecil dan terdapat variabel lain yang mempengaruhi fraudulent financial statement seperti variabel pertumbuhan perusahaan, nature of 
Jurnal Akuntansi Bisnis, Vol. 19, No. 1, Maret 2021 ISSN 1412-775X (media cetak) | 2541-5204 (media online)

industry, kualitas auditor eksternal, hubungan dengan pihak berelasi, opini audit, whistleblowing system, change audit committee, e-procerement, CEO education, CEO military, dan auditor fee. Penelitian selanjutnya juga diharapkan menambahkan variabel moderating atau intervening yang dapat melemahkan atau memperkuat hubungan antara variabel dependen dengan variabel independen.

\section{DAFTAR PUSTAKA}

ACFE. (2017). Fraud Examiners Manual. ACFE, 1913.

Akbar, T. 2017. The Determination Of Fraudulent Financial Reporting Causes By Using Pentagon Theory On Manufacturing Companies In Indonesia. International Journal Of Business, Economics And Law, Vol. 14, Issue 5 (December) Issn 2289-1552, 14(5), 106-113.

Aprilia. 2017. Analisis Pengaruh Fraud Pentagon Terhadap Kecurangan Laporan Keuangan Menggunakan Beneish Model Pada Perusahaan Yang Menerapkan Asean Corporate Governance Scorecard. Jurnal Aset (Akuntansi Riset), 9(1), 101-132.

Association Of Certified Fraud Examiners (ACFE). 2020. Report To The Nations On Occupational Fraud And Abuse: 2020 Global Fraud Study. Acfe, 88.

Aviantara, R. 2021. Scoring The Financial Distress And The Financial Statement Fraud Of Garuda Indonesia With DDCC As The Financial Solutions. Journal Of Modelling In Management. Https://Doi.Org/10.1108/Jm2-01-2020-0017

Dumaria, N., dan Majidah. 2019. Pengaruh Fraud Pentagon Terhadap Deteksi Fraudulent Financial Reporting Dengan Menggunakan Metode Beneish M-Score Model ( Studi Empiris Pada Perusahaan Sektor Pertambangan Yang Terdaftar Di Bursa Efek Indonesia Pada Tahun 2014 - 2017 ). Eproceedings Of Management : Vol.6, No.2 Agustus 2019| Page 3148. Telkom University, 6(2), 3148-3156.

Faradiza, S. A. 2019. Fraud Pentagon Dan Kecurangan Laporan Keuangan. 4988, 1-22.

Fitria. 2013. Pengaruh Kemampuan Manajerial Dan Koneksi Politik Terhadap Reaksi Investor Dengan Kecurangan Laporan Keungan. Journal Of Chemical Information And Modeling, 53(9), 1689-1699.

Frymaruwah, E., Akuntansi, J., dan Sriwijaya, P. N. 2020. Aalisis Fraud Triangle Dalam Mendeteksi Kecurangan Laporan Keuangan Emiten Sektor Pertambangan. In Jurnal Akuntanika 6 (2).

G, C. T. dan P. Hartono. 2016). Fraudulent Financial Reporting : Pengujian Teori Fraud Pentagon Pada Sektor Keuangan Dan Perbankan Di Indonesia. Simposium Nasional Akuntansi Xix, Lampung, 2016, 1-21.

Jensen, M. C., dan W. H. Meckling. 1976. Theory Of The Firm: Managerial Behavior, Agency Costs And Ownership Structure. Journal Of Financial Economics, 3(4), 305-360. Https://Doi.Org/10.1016/0304-405x(76)90026-X 
Jurnal Akuntansi Bisnis, Vol. 19, No. 1, Maret 2021

ISSN 1412-775X (media cetak) | 2541-5204 (media online)

Kusumosari, L., DAN Solikhah, B. 2020. Fraud Hexagon Pada Perusahaan Manufaktur Yang Terdaftar Di Bursa Efek Indonesia Tahun 2014-2018. 1-16.

Lastanti, H. S. 2020. Role Of Audit Committee In The Fraud Pentagon And Financial Statement Fraud. International Journal Of Contemporary Accounting, 2(1), 77. Https://Doi.Org/10.25105/Ijca.V2i1.7163

Omukaga, K. O. 2019. Is The Fraud Diamond Perspective Valid In Kenya? Https://Doi.Org/10.1108/Jfc-11-2019-0141

Ozcelik, H. 2020. An Analysis Of Fraudulent Financial Reporting Using The Fraud Diamond Theory Perspective: An Empirical Study On The Manufacturing Sector Companies Listed On The Borsa Istanbul. 102, 131-153. Https://Doi.Org/10.1108/S1569-375920200000102012

Pamungkas, I. D., I. Ghozali, dan T. Achmad. 2018. A Pilot Study Of Corporate Governance And Accounting Fraud: The Fraud Diamond Model. Journal of Business and Retail Management Research 12 (2).

Putri, L. L., dan D. Deviesa. 2017. Pengaruh Ceo Duality Terhadap Financial Performance Dengan Earnings Management Sebagai Variabel Intervening. Business Accounting Review, 5(1), 169-180.

Sabrina, O. Z., P. P. Midiastuty, dan E. Suranta. 2020. Pengaruh Koneksitas Organ Corporate Governance, Ineffective Monitoring Dan Manajemen Laba Terhadap Fraudulent Financial Reporting Jurnal Akuntansi, Keuangan, dan Manajemen, 1(2), 109-122.

Sari, S. P., dan N. K. Nugroho. 2020. Financial Statements Fraud Dengan Pendekatan Vousinas Fraud Hexagon Model: Tinjauan Pada Perusahaan Terbuka Di Indonesia. 1st Annual Conference Of Ihtifaz, 409-430.

Http://Seminar.Uad.Ac.Id/Index.Php/Ihtifaz/Article/Download/3641/1023

Septriyani, Y., dan D. Handayani. 2018. Mendeteksi Kecurangan Laporan Keuangan Dengan Analisis Fraud Pentagon. Jurnal Akuntansi, Keuangan Dan Bisnis, 11(1), 11-23. Http://Jurnal.Pcr.Ac.Id

Sihombing, K. S., S. N. Rahardjo. 2014. Analisis Fraud Diamond Dalam Mendeteksi Financial Statement Fraud : Studi Empiris Pada Perusahaan Manufaktur Yang Terdaftar Di Bursa Efek Indonesia ( Bei ) Tahun 2010-2012. Diponegoro Journal of Accounting 03, 1-12.

Skousen, C. J., K. R. Smith, dan C. J. Wright. 2009. Detecting And Predicting Financial Statement Fraud: The Effectiveness Of The Fraud Triangle And Sas No. 99 In Corporate Governance And Firm Performance. In International Journal Of Quality \& Reliability Management (Vol. 32, Issue 3).

Sudarmanto, E. 2020. Manajemen Risiko : Deteksi Dini Upaya Pencegahan Fraud. 9(2), 107-121.

Syahria, R. 2019. Detecting Financial Statement Fraud Using Fraud Diamond (A Study On Banking Companies Listed On The Indonesia Stock Exchange Period 2012-2016). In Asia Pacific Fraud Journal 4 (2). Https://Doi.Org/10.21532/Apfjournal.V4i2.114 
Jurnal Akuntansi Bisnis, Vol. 19, No. 1, Maret 2021 ISSN 1412-775X (media cetak) | 2541-5204 (media online)

Vidella, A., dan E. T. Afiah. 2020. Financial Stability, Financial Targets, Effective Monitoring Dan Rationalization Dan Kecurangan Laporan Keuangan. Jurnal Revenue, 01(01), 90-100.

Vousinas, G. L. 2019. Advancing Theory Of Fraud: The S.C.O.R.E. Model. Journal Of Financial Crime, 26(1), 372-381. Https://Doi.Org/10.1108/Jfc-12-2017-0128

Wang, Z., M. H. Chen, C. L. Chin, dan Q. Zheng. 2017. Managerial Ability, Political Connections, And Fraudulent Financial Reporting In China. Journal Of Accounting And Public Policy, 36(2), 141-162. Https://Doi.Org/10.1016/J.Jaccpubpol.2017.02.004

Wolfe, D. T., dan D. R. Hermanson. 2004. The Fraud Diamond : Considering The Four Elements Of Fraud: Certified Public Accountant. The Cpa Journal, 74(12): 38-42.

Yang, D., H. Jiao, dan R. Buckland. 2017. Technological Forecasting \& Social Change The Determinants Of Fi Nancial Fraud In Chinese Fi Rms : Does Corporate Governance As An Institutional Innovation Matter? Technological Forecasting \& Social Change, December 2016, 0-1. Https://Doi.Org/10.1016/J.Techfore.2017.06.035

Yassha, A., dan M. Zahara. 2020. Crowe's Fraud Pentagon Dalam Mengindikasikan Kecurangan Laporan Keuangan. Http://Trilogi.Ac.Id/Journal/Ks/Index.Php/Epakt/Article/View/766

Yusrianti, H., I. Ghozali, E. Yuyetta, Aryanto, dan E. Meirawati. 2020. Financial Statement Fraud Risk Factors Of Fraud Triangle: Evidence From Indonesia. International Journal of Financial Research, 11(4), 36-51. Https://Doi.Org/10.5430/Ijfr.V11n4p36

Zaki, N. M. 2017. The Apporiateness Of Fraud Triangel And Diamond Models In Assessing The Like In Assessing The Likelihood Of Fraudulent Financial Statements- An Empirical Study On Firms Listed In The Egyptian Stock Exchange . International Journal Of Social Science And Economic Research, 02, 2403-2433. 